\title{
PERIÓDICO ESPAÇO E CULTURA: TRAJETÓRIA PESSOAL E IMPACTO ACADÊMICO
}

- HEBERT GUILHERME DE AZEVEDO ${ }^{1}$

${ }^{1}$ Mestre em Geografia (UERJ). E-mail para contato: azevedo.hebert@gmail.com

Recebido em:10/07/2020

Aprovado em: 22/01/2021

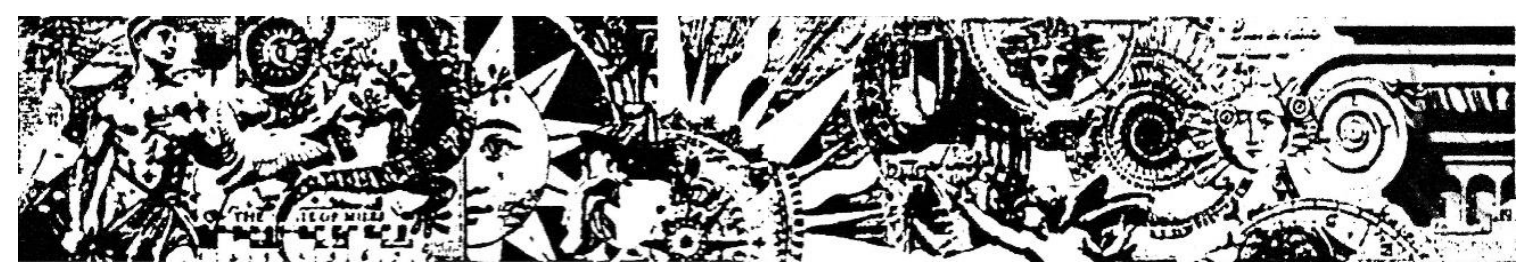

\section{Introdução}

O presente artigo foi produzido a convite dos editores do periódico Espaço e Cultura, sob a encomenda de apresentar minha experiência no tempo em que atuei na editoração da revista e uma reflexão sobre o impacto desta na Geografia Cultural no Brasil. Assim está estruturado o artigo: na primeira parte apresento um pouco da minha trajetória de suporte operacional da produção do periódico e na segunda apresento alguns elementos para pensar o impacto dele nesse campo do pensamento geográfico brasileiro. Ao final são apresentadas algumas considerações sobre as questões tratadas ao longo do texto.

\section{Trajetória pessoal}

Era o ano de 2005 quando entrei nos corredores da UERJ pela primeira vez, para realizar minha matrícula no curso de Geografia. Um misto de sentimentos se 
colocava naquele lugar e naquele momento: a alegria de ter ingressado na universidade - o primeiro da família-, a ansiedade quanto ao que me esperava ali - como seria o curso? - e a incerteza quanto à continuidade - conseguiria cursar até o final?

Em meio a tantas questões, fui passeando pelos corredores, quando me deparei com uma placa que indicava "NEPEC - Núcleo de Estudos e Pesquisas sobre Espaço e Cultura". Aquilo me chamou atenção, o que seria? Nos anos escolares não tinha estudado esta relação. Tão logo tive a oportunidade me apresentei à professora Zeny Rosendahl, colocando a ela meu interesse em participar do núcleo. Assim começou minha trajetória no núcleo, onde fui bolsista ao longo de quatro anos (2005 - 2009, quando conclui a graduação), atuando nos simpósios nacionais e internacionais sobre Espaço e Cultura e, principalmente, no apoio operacional para a publicação da revista Espaço e Cultura. Neste período participei da produção de sete edições (Números 22 a 27 e a Edição Comemorativa de 15 anos do NEPEC em 2008).

As atividades que eu exercia diziam respeito ao suporte técnico e operacional da revista, consistindo, de maneira sucinta, nas seguintes etapas:

a) recebimento e organização dos originais em formato digital;

b) impressão e organização destes originais em formato impresso para envio à revisora;

c) interface com a revisora para recebimento das correções dos originais impressos, correção dos arquivos em formato digital e, quando necessário, comunicação com os autores para correções que fossem estruturais;

d) interlocução com o diagramador e avaliação do produto entregue, conferindo se o resultado estava de acordo com a identidade visual da revista;

e) envio e acompanhamento da equipe responsável pela disponibilização online;

f) comunicação com os autores para notificar da publicação de seus artigos.

Além de ter trabalhado na revista nesse período, tive a felicidade de publicar um artigo na edição 28 intitulado "Geografia e espiritismo: o conceito de espaço sagrado e a teoria da difusão espacial das inovações na construção da pesquisa”, cujo objetivo foi 
destacar as relações entre a Geografia e a religião espírita a partir de duas óticas, particulares por sua construção, mas empiricamente imbricadas, quais seja: a visão de mundo do espírita enquanto homem religioso e seu modo de identificar e qualificar o espaço, e a visão do espiritismo enquanto instituição a partir do conceito de espaço sagrado e da apresentação da teoria da difusão espacial das inovações e sua aplicação ao estudo da espacialidade institucional espírita e da política da religião no espaço. (AZEVEDO, 2010, p.1)

Para concluir esta seção gostaria de agradecer a todos com quem trabalhei durante esse período e, em especial, à professora Zeny Rosendahl, com a certeza de que grande parte da minha trajetória pessoal e profissional se deve a tudo que tive a oportunidade de aprender no NEPEC.

\section{Impacto acadêmico do periódico Espaço e Cultura}

O periódico Espaço e Cultura encontra-se classificado na categoria B1 do portal da CAPES. Tal classificação demonstra o reconhecimento da comunidade acadêmica em relação à revista. Neste sentido, vamos apresentar alguns elementos que certamente contribuem para esta classificação e que demonstram a importância desta revista no campo de estudo da Geografia Cultural.

Um primeiro elemento a ser destacado é a longevidade da revista, no de 2020 completam-se 25 anos de publicação. Ao longo desse tempo, foram 47 números em 44 edições, nos quais foram publicados 347 textos, a distribuição destes textos em suas respectivas edições está representada na tabela a seguir.

\begin{tabular}{|c|c|c|c|c|c|}
\hline Edição & & Ano & Artigos & Traduções & Resenhas \\
\hline & 1 & 1995 & 4 & & \\
\hline & 2 & 1996 & 4 & & 1 \\
\hline & 3 & 1997 & 4 & 1 & 1 \\
\hline & 4 & 1997 & 4 & 1 & 1 \\
\hline & 5 & 1998 & 4 & 1 & 1 \\
\hline & 6 & 1998 & 4 & 1 & 1 \\
\hline & 7 & 1999 & 1 & 4 & 1 \\
\hline & 8 & 1999 & 3 & 2 & 1 \\
\hline 9 e 10 & & 2000 & 5 & & 1 \\
\hline 11 e 12 & & 2001 & 9 & & 1 \\
\hline & 13 & 2002 & 2 & 2 & 1 \\
\hline & 14 & 2002 & & 4 & 1 \\
\hline & 15 & 2003 & 7 & & \\
\hline & 16 & 2003 & 2 & 3 & 1 \\
\hline
\end{tabular}




\begin{tabular}{|c|c|c|c|c|c|}
\hline 17 e 18 & & 2004 & 12 & & \\
\hline \multirow[t]{3}{*}{19 e 20} & & 2005 & 9 & & \\
\hline & 21 & 2007 & 8 & & \\
\hline & 22 & 2007 & 7 & & \\
\hline \multirow[t]{26}{*}{2008 - Edição Comemorativa (1993 - 2008) } & & 2008 & 7 & 7 & \\
\hline & 23 & 2008 & 7 & & \\
\hline & 24 & 2008 & 5 & & 1 \\
\hline & 25 & 2009 & 9 & & \\
\hline & 26 & 2009 & 6 & & \\
\hline & 27 & 2010 & 6 & & \\
\hline & 28 & 2010 & 9 & & 1 \\
\hline & 29 & 2011 & 6 & & \\
\hline & 30 & 2011 & 7 & & \\
\hline & 31 & 2012 & 8 & & \\
\hline & 32 & 2012 & 6 & & 1 \\
\hline & 33 & 2013 & 10 & 3 & 1 \\
\hline & 34 & 2013 & 8 & 1 & 1 \\
\hline & 35 & 2014 & 9 & & \\
\hline & 36 & 2014 & 10 & & \\
\hline & 37 & 2015 & 10 & & 1 \\
\hline & 38 & 2015 & 10 & 1 & 1 \\
\hline & 39 & 2016 & 9 & 6 & \\
\hline & 40 & 2016 & 9 & & \\
\hline & 41 & 2017 & 8 & & \\
\hline & 42 & 2017 & 6 & & 1 \\
\hline & 43 & 2018 & 7 & & 1 \\
\hline & 44 & 2018 & 7 & & 1 \\
\hline & 45 & 2019 & 6 & & \\
\hline & 46 & 2019 & 6 & 1 & \\
\hline & 47 & 2020 & 7 & & \\
\hline Subtotal & & & 287 & 38 & 22 \\
\hline Total & & & & & 347 \\
\hline
\end{tabular}

Tabela 1: Distribuição dos textos classificados por tipo nas edições da revista Espaço e Cultura (1995 2020)

Fonte: Organizada pelo autor, 2020.

O segundo elemento a ser destacado é que, além dos 287 artigos, foram publicadas na revista 38 traduções, que disponibilizam, em português, textos relevantes originalmente produzidos em língua estrangeira e 22 resenhas que trazem uma visão crítica de livros voltados à temática. Em especial, destaca-se a discussão sobre a ideia de cultura na Geografia, envolvendo os artigos de Don Mitchell (2008a), que apresenta crítica a visão de cultura com status ontológico, redimensionando a discussão para a ideia de cultura, Peter Jackson (2008), por sua vez, faz uma réplica a 
esta visão, criticando o risco de se perder de vista a materialidade da cultura, Denis Cosgrove (2008), apresenta três argumentos para redimensionar as críticas expostas por Mitchell: a) ter ignorado os trabalhos monográficos, avaliando somente textos teóricos ou programáticos, b) a crítica ao uso de metáforas espaciais para referir-se a cultura e c) a leitura de cultura reduzida a um campo de contestações de poder, James Duncan e Nancy Duncan (2008), por outro lado afirmam que Mitchell incorre justamente no ponto em que critica, dar a cultura um status ontológico e que faltam referências a trabalhos empíricos, Don Mitchell (2008a) que apresenta suas ponderações acerca dos textos anteriores e a leitura desta discussão fornecida por Scott William Hoefle (2008).

O terceiro elemento é a disponibilidade das edições e o seu papel na democratização do conhecimento no espoco da Geografia Cultural. Atualmente todas as edições encontram-se disponíveis no endereço eletrônico https://www.epublicacoes.uerj.br/index.php/espacoecultura, garantindo amplo acesso à comunidade acadêmica.

O quarto elemento que destacamos neste texto é que o periódico foi objeto de estudo da tese de doutoramento de Almir Nabozny (2014), bem como as teses e dissertações produzidas no campo da Geografia Cultural, que afirma

Ao responder sua pergunta sobre as tensões que resultaram na produção científica de Geografia Cultural no Brasil é necessário relembrar o lugar e o período da difusão desta ideia da abordagem cultural na Geografia Brasileira. O lugar foi e é o NEPEC Núcleo de Estudos e Pesquisas sobre Espaço e Cultura. (NABOZNY, 2014, p.218)

Por fim, para estimar o impacto na produção acadêmica derivado da revista em outras produções acadêmicas, foram levantadas as citações indexadas na plataforma Google Acadêmico. Além da revista Espaço e Cultura, levantaram-se as citações das revistas GeoUERJ (1997 - 2020) e GeoUSP (1997 - 2020). Ressalte-se que a revista Espaço e Cultura é voltada a um subcampo específico da Geografia, enquanto as demais abordam temas diversos. Considerando o que foi dito anteriormente, podemos afirmar que, apesar de apresentar um número menor de citações, este é expressivo, dada a especialidade a que se destina. Os resultados obtidos estão expressos na tabela a seguir. 


\begin{tabular}{lccc}
\hline Revista & Espaço e Cultura & GeoUERJ & GeoUSP \\
\hline Citações & 302 & 801 & 1492 \\
\hline Tabela 2: Distribuição dos textos classificados por tipo nas edições da revista Espaço e Cultura (1995 - & 2020) \\
\multicolumn{4}{c}{ Fonte: Organizada pelo autor. }
\end{tabular}

A partir dos elementos elencados anteriormente, podemos afirmar que a revista Espaço e Cultura foi e ainda é um importante instrumento de divulgação científica no campo da Geografia Cultural no Brasil.

\section{Considerações Finais}

O periódico Espaço e Cultura deixou profundas marcas na formação do campo da Geografia Cultural, sendo um importante referencial na publicação da produção acadêmica brasileira, na tradução de textos em outros idiomas e na apresentação de novos textos sob a forma de resenha. Sua longevidade, qualidade das publicações e disponibilidade justificam o caráter central que ocupa em seu campo científico.

A formação do geógrafo que escreve este artigo também foi profundamente impactada, pois a atuação na revista o ensinou conceitos fundamentais para o desenvolvimento profissional: compromisso, seriedade, prazo, interlocução, dentre tanto outros. Por isso, não poderia encerrar com outra palavra diferente de “obrigado”!

\section{REFERÊNCIAS BIBLIOGRÁFICAS}

AZEVEDO, Hebert Guilherme de Azevedo. Geografia e espiritismo: o conceito de espaço sagrado e a teoria da difusão espacial das inovações na construção da pesquisa. Espaço e Cultura. n. $28,2010$.

COSGROVE, Denis. Idéias e cultura: uma resposta a Don Mitchell. Espaço e Cultura. Edição comemorativa 1993 - 2008, 2008.

DUNCAN, James e DUNCAN, Nancy. Reconceitualização a idéia de cultura em geografia: uma resposta a Don Mitchell. Espaço e Cultura. Edição comemorativa 1993 - 2008, 2008.

HOEFLE, Scott William. Debates recentes na geografia cultural anglo-americana: uma apreciação antropológica e filosófica. Espaço e Cultura. Edição comemorativa 1993 - 2008, 2008.

JACKSON, Peter. A idéia de cultura: uma resposta a Don Mitchell. Espaço e Cultura. Edição comemorativa 1993 - 2008, 2008.

MITCHELL, Don. Não existe aquilo que chamamos de cultura: para uma reconceitualização da idéia de cultura em geografia. Espaço e Cultura. Edição comemorativa 1993 - 2008, 2008. 
MITCHELL, Don. Explicação em geografia cultural: uma resposta a Cosgrove, Jackson e aos Duncans. Espaço e Cultura. Edição comemorativa 1993 - 2008, 2008.

NABOZNY, Almir. Abordagens culturais na geografia brasileira: uma compreensão. 2014. 290f. Tese (Doutorado em Geografia) - Instituto de Geociências, Universidade Federal do Rio Grande do Sul, Porto Alegre, 2014. 